\title{
Activated Microglia Contribute to the Maintenance of Chronic Pain after Spinal Cord Injury
}

\author{
Bryan C. Hains and Stephen G. Waxman \\ Department of Neurology and Center for Neuroscience and Regeneration Research, Yale University School of Medicine, New Haven, Connecticut 06510, \\ and Rehabilitation Research Center, Virginia Connecticut Healthcare System, West Haven, Connecticut, 06516
}

Traumatic spinal cord injury (SCI) results not only in motor impairment but also in chronic central pain, which can be refractory to conventional treatment approaches. It has been shown recently that in models of peripheral nerve injury, spinal cord microglia can become activated and contribute to development of pain. Considering their role in pain after peripheral injury, and because microglia are known to become activated after SCI, we tested the hypothesis that activated microglia contribute to chronic pain after SCI. In this study, adult male Sprague Dawley rats underwent T9 spinal cord contusion injury. Four weeks after injury, when lumbar dorsal horn multireceptive neurons became hyperresponsive and when behavioral nociceptive thresholds were decreased to both mechanical and thermal stimuli, intrathecal infusions of the microglial inhibitor minocycline were initiated. Electrophysiological experiments showed that minocycline rapidly attenuated hyperresponsiveness of lumbar dorsal horn neurons. Behavioral data showed that minocycline restored nociceptive thresholds, at which time spinal microglial cells assumed a quiescent morphological phenotype. Levels of phosphorylatedp38 were decreased in SCI animals receiving minocycline. Cessation of delivery of minocycline resulted in an immediate return of pain-related phenomena. These results suggest an important role for activated microglia in the maintenance of chronic central belowlevel pain after SCI and support the newly emerging role of non-neuronal immune cells as a contributing factor in post-SCI pain.

Key words: microglia; sensitization; dorsal horn; pain; spinal cord injury; hypersensitivity

\section{Introduction}

Chronic pain and sensory dysesthesia that develop after spinal cord injury (SCI) are resistant to conventional therapeutic approaches, suggesting a complex etiology of many contributing factors (Hulsebosch, 2005). Indeed, anatomical, neurochemical, excitotoxic, inflammatory, and alterations in ion channel expression all contribute to chronic pain after SCI (Hains et al., 2001, 2003a,b, 2005; Finnerup and Jensen, 2004; Waxman and Hains, 2006). Randomized clinical trials targeting a number of these putative factors have examined anticonvulsants (Finnerup et al., 2002), selective serotonin reuptake inhibitors and tricyclic antidepressants (Davidoff et al., 1987; Cardenas et al., 2002), sodium channel blockers (Loubser and Donovan, 1991; Finnerup et al., 2005), and opioids (Attal et al., 2002; Siddall et al., 2000) and have shown limited relief from some forms of pain after SCI.

Until very recently, pain has been thought to arise primarily from the dysfunction of neurons. Recent evidence, however, suggests that neuroimmune alterations may also contribute to pain

Received Jan. 2, 2006; revised March 14, 2006; accepted March 14, 2006

This work was supported in part by grants from the Medical Research Service and Rehabilitation Research Service, Department of Veterans Affairs, and the National Multiple Sclerosis Society. The Center for Neuroscience and Regeneration Research is a Collaboration of the Paralyzed Veterans of America and the United Spinal Association. B.C.H. was supported by The Christopher Reeve Paralysis Foundation (HB1-0304-2), the National Institutes of Health/ National Institute of Neurological Disorders and Stroke (1 F32 NS046919-01), and Pfizer (Scholar's Grant in Pain Medicine). We thank Dr. Joel Black for valuable experimental advice and Bart Toftness for technical assistance.

Correspondence should be addressed to Dr. Stephen G. Waxman, Department of Neurology, Yale University School of Medicine, 333 Cedar Street, LCI-707, New Haven, CT 06510. E-mail: stephen.waxman@yale.edu. DOl:10.1523/JNEUROSCI.0003-06.2006

Copyright $\odot 2006$ Society for Neuroscience $\quad$ 0270-6474/06/264308-10\$15.00/0 after injury to the nervous system. Glial cells involved in mediating inflammatory processes are resident within the spinal cord and include both astroglia and microglia; the latter of which has been implicated directly in the initiation of peripheral injuryinduced pain (Watkins et al., 2001). Activation of spinal microglia after peripheral injury can be induced by partial sciatic nerve ligation (Coyle, 1998), formalin injection (Fu et al., 1999), spinal nerve ligation (Jin et al., 2003), and sciatic nerve inflammation (Ledeboer et al., 2005). Early or late delivery of the microglial inhibitor minocycline can result in different effects on pain phenomenology (Raghavendra et al., 2003; Hua et al., 2005; Ledeboer et al., 2005). Conversely, the microglial activator fractalkine can produce behavioral signs of allodynia and hyperalgesia (Milligan et al., 2004).

Although spinal microglia have been studied after peripheral injury, little is known about their role in pain after central injury or SCI. Microglial activation has been documented in the spinal cord after contusive SCI (Popovich et al., 1997; Sroga et al., 2003; Nesic et al., 2005; Zai and Wrathall, 2005) and has been shown to occur as far caudal as the lumbar enlargement after thoracic injury (Hains et al., 2003b). A number of studies have demonstrated the neuroprotective effects of acute minocycline administration (Lee et al., 2003; Stirling et al., 2004; Teng et al., 2004). Although recently associated with at-level chronic pain (Nesic et al., 2005; Crown et al., 2006), no studies have specifically examined the role of microglia in the development or maintenance phases of chronic below-level pain after SCI.

Given that there are data supporting the involvement of mi- 
croglia in pain after peripheral injury and work showing chronic post-SCI activation of microglia, we hypothesized that activated spinal microglia play a role in chronic central pain after SCI. Here, we report that thoracic SCI causes chronic activation of microglia in the lumbar spinal cord and that these activated microglia contribute to the maintenance of neuronal hyperresponsiveness and pain-related behaviors.

\section{Materials and Methods}

Animal care. Experiments were performed in accordance with National Institutes of Health Guidelines for the Care and Use of Laboratory Animals; all animal protocols were approved by the Yale University Institutional Animal Use Committee. Adult male Sprague Dawley rats (200-225 g) were used for this study. Animals were housed under a $12 \mathrm{~h} \mathrm{light/dark}$ cycle in a pathogen-free area with free access to water and food.

Spinal cord contusion injury. Rats were deeply anesthetized with ketamine/xylazine $(80 / 5 \mathrm{mg} / \mathrm{kg}$, i.p.). SCI was produced ( $n=42 \mathrm{rats})$ at spinal segment T9 using the New York University impact injury device (Gruner 1992). A $10 \mathrm{~g}, 2.0$-mm-diameter rod was released from a $25 \mathrm{~mm}$ height onto the exposed spinal cord. For sham surgery, animals ("intact," $n=10$ ) underwent laminectomy and placement into the vertebral clips of the impactor without impact injury. After SCI or sham surgery, the overlying muscles and skin were closed in layers with $4-0$ silk sutures and staples, respectively, and the animal was allowed to recover on a $30^{\circ} \mathrm{C}$ heating pad. Postoperative treatments included saline $(2.0 \mathrm{cc}$, s.c.) for rehydration and Baytril $(0.3 \mathrm{cc}, 22.7 \mathrm{mg} / \mathrm{ml}$, s.c., twice daily) to prevent urinary tract infection. Bladders were manually expressed twice daily until reflex bladder emptying returned, typically by $10 \mathrm{~d}$ after injury. After surgery, animals were maintained under the same preoperative conditions and fed ad libitum.

Intrathecal catheterization and drug delivery. Twenty-eight days after SCI, under ketamine/xylazine ( $80 / 5 \mathrm{mg} / \mathrm{kg}$, i.p.) anesthesia, a sterile premeasured $32 \mathrm{G}$ intrathecal (i.t.) catheter (ReCathCo, Allison Park, PA) was introduced through a slit in the atlanto-occipital membrane, threaded down to the lumbar enlargement, secured to the neck musculature with suture, and heat sealed to prevent infection and leakage of CSF ( $n=36$ animals). Tip location was verified after the animal was killed. Animals were used for behavioral analysis daily from days 30-35 ( $n=8 / \mathrm{d} /$ group), killed for histological analysis on day 33 ( $n=6 /$ group), and used for electrophysiological experiments on day 34 ( $1 \mathrm{~d}$ after $3 \mathrm{~d}$ of drug administration; $n=4$ /group).

Three days after catheter placement (day 31 after SCI), under brief $(<1$ $\mathrm{min}$ ) halothane sedation ( $3 \%$ by facial mask), i.t. infusion of either vehicle ( $n=18$ animals) or minocycline ( $n=18$ animals) began. The tetracycline antibiotic minocycline has been shown to inhibit inflammatory cytokines, free radicals production, and matrix metalloproteinases (Stirling et al., 2005) and potently downregulates the activity of microglia in vivo (Raghavendra et al., 2003; Hua et al., 2005; Ledeboer et al., 2005). 7-Dimethylamino-6-demethyl-6-deoxytetracycline (100 $\mu \mathrm{g}$; minocycline hydrochloride, molecular weight, 493.9; Sigma, St. Louis, MO) was used based on previous reports (Ledeboer et al., 2005) and preliminary electrophysiological experiments. For $3 \mathrm{~d}, 100 \mu \mathrm{g} / 5 \mu \mathrm{l}$ minocycline was injected twice daily in artificial CSF (aCSF; $1.3 \mathrm{~mm} \mathrm{CaCl} \cdot 2 \mathrm{H}_{2} \mathrm{O}, 2.6 \mathrm{~mm}$ $\mathrm{KCl}, 0.9 \mathrm{~mm} \mathrm{MgCl}, 21.0 \mathrm{~mm} \mathrm{NaHCO}_{3}, 2.5 \mathrm{~mm} \mathrm{Na}_{2} \mathrm{HPO}_{4} \cdot 7 \mathrm{H}_{2} \mathrm{O}, 125.0$ $\mathrm{mm} \mathrm{NaCl}$, prepared in sterile $\mathrm{H}_{2} \mathrm{O}$ ), followed by $10 \mu \mathrm{l}$ of aCSF flush. As a vehicle control, aCSF was injected during the same time points as minocycline in separate animals.

Immunocytochemistry. Tissue was collected from the lumbar enlargement (L4 spinal segment) of animals from the following groups: intact $(n=6)$, SCI plus vehicle $(n=6)$, or SCI plus minocycline $(n=6)$. Rats were deeply anesthetized with ketamine/xylazine $(80 \mathrm{mg} / 5 \mathrm{~kg}$, i.p.) and perfused intracardially with $0.01 \mathrm{~m}$ PBS followed by $4 \%$ cold, buffered paraformaldehyde. Tissue was postfixed for $15 \mathrm{~min}$ in $4 \%$ paraformaldehyde and cryopreserved overnight at $4^{\circ} \mathrm{C}$ in $30 \%$ sucrose PBS. Thin $(8$ $\mu \mathrm{m})$ cryosections ( $n=6$ sections/animal) from each treatment group were processed simultaneously.

Slides were incubated at room temperature in the following: (1) blocking solution (PBS containing 5\% NGS, 2\% BSA, 0.1\% Triton X-100, and
$0.02 \%$ sodium azide) for $30 \mathrm{~min}$; (2) primary antibody: mouse anti$\mathrm{CD} 11 \mathrm{~b} / \mathrm{c}$ OX-42 clone raised against compliment receptor 3 (1:250; BD Biosciences, San Jose, CA), rabbit anti-phosphorylated p38 (P-p38) (1: 50; Cell Signaling Technology, Danvers, MA), or mouse anti-GFAP (1: 500; Chemicon, Temecula, CA) overnight in blocking solution at $4^{\circ} \mathrm{C}$; (3) PBS, six times for 5 min each; (4) either goat anti-rabbit Alexa 488 or 546 (1:1500; Invitrogen, Eugene, OR), donkey anti-mouse 546 (1:1500; Invitrogen), or rabbit anti-mouse IgG-biotin (1:1000; Sigma) in blocking solution for $2 \mathrm{~h}$; (5) PBS, six times for 5 min each. Biotin slides were incubated in avidin-HRP (1:1000; Sigma) in blocking solution for $2 \mathrm{~h}$; PBS, six times for $5 \mathrm{~min}$ each; and heavy metal-enhanced DAB (Pierce, Rockford, IL) for $7 \mathrm{~min}$, followed by PBS, three times for $5 \mathrm{~min}$ each. Control experiments were performed without primary or secondary antibodies that yielded only background levels of signal.

Quantitative image analysis. Images were captured with a Nikon Eclipse E800 light microscope equipped with epifluorescence and Nomarski optics, using a Photometrics CoolSnap HQ camera (Roper Scientific, Tucson, AZ) and MetaVue v6.2r6 software (Universal Imaging Corporation, Downingtown, PA). Quantitative analysis was performed by a blinded observer using MetaVue and IPLab Spectrum v3.0 software (Scanalytics, Fairfax, VA). For cell density determination, the number of positively labeled cells was counted for a predefined area of dorsal horn. Percentage of field analysis was used to provide a quantitative estimate (proportional area) of changes in the activation state of glial cells (Popovich et al., 1997; Kigerl et al., 2006). Resting and activated astroglia or microglia were classified based on the following criteria. Resting glia displayed small compact somata bearing long, thin, ramified processes. Activated glia exhibited marked cellular hypertrophy and retraction of processes such that the process length was less than the diameter (D) of the soma compartment. Cells were sampled only if the nucleus was visible within the plane of section and if cell profiles exhibited distinctly delineated borders. Background levels of signal were subtracted, and control and experimental conditions were evaluated in identical manners.

Electrophysiologic procedures. Two groups of animals were used for extracellular unit recordings. Group 1 was comprised of SCI animals that underwent acute drug administration $30 \mathrm{~d}$ after injury. Group 2 was comprised of intact animals and SCI animals that received either i.t. vehicle or minocycline for $3 \mathrm{~d}$ (starting on day 31). Recordings were made on day 34 , corresponding to $1 \mathrm{~d}$ after cessation of drug delivery in SCI plus vehicle and SCI plus minocycline groups.

Acute spinal drug delivery (group 1) was performed by soaking drug solutions onto pledgets $\left(2 \mathrm{~mm}^{2}\right)$, which were placed centered on the dorsal surface of the spinal segment where cells were isolated, covering both ipsilateral and contralateral dorsal horns $(n=2$ animals per dose; 10, 100, and $200 \mu \mathrm{g}$ ) (Qin et al., 1999; Hains et al., 2003a). Incremental dosing relationships were constructed by averaging the mean response for each drug concentration and expressing the mean response as percentage of predrug response (set to $100 \%$ ). $\mathrm{ID}_{50}$ values were calculated from sigmoid curves fitted to the cumulative concentration-response data using the following formula for nonlinear regression: $f=y 0+a /(1$ $+\exp [-(x-x 0) / b)]$, where $a$ is top plateau, $b$ is slope, $x 0$ is $\log \operatorname{ID}_{50}$, and $y 0$ is bottom plateau. Minocycline was dissolved in $5 \mu \mathrm{l}$ of aCSF, pH 7.4. Mineral oil was drawn off and replaced before and immediately after pledget application. The start time of recordings was based on predetermined onset and offset efficacy evaluations. PBS vehicle control pledgets were applied in the same manner before or after drug application to ensure continuity of response. Pledgets remained on the lumbar cord for $60 \mathrm{~min}$, and then the dorsal aspect of the spinal cord was flushed with PBS. At least $30 \mathrm{~min}$ elapsed between each application to allow for washout.

Animals from groups 1 and 2 underwent extracellular single-unit recording according to established methods (Hains et al., 2003a,b). The activity of 3-7 U/animal ( $n=4$ /group) were recorded for each experiment, yielding 6-28 cells/group. Rats were initially anesthetized with sodium pentobarbital ( $40 \mathrm{mg} / \mathrm{kg}$, i.p.) and supplemented $(5 \mathrm{mg} / \mathrm{kg} / \mathrm{h})$ intravenously through a catheter in the jugular vein. Rectal temperature was maintained at $37^{\circ} \mathrm{C}$ by a thermostatically controlled heating blanket. A T12-L6 laminectomy was done before fixing the head and the vertebral 

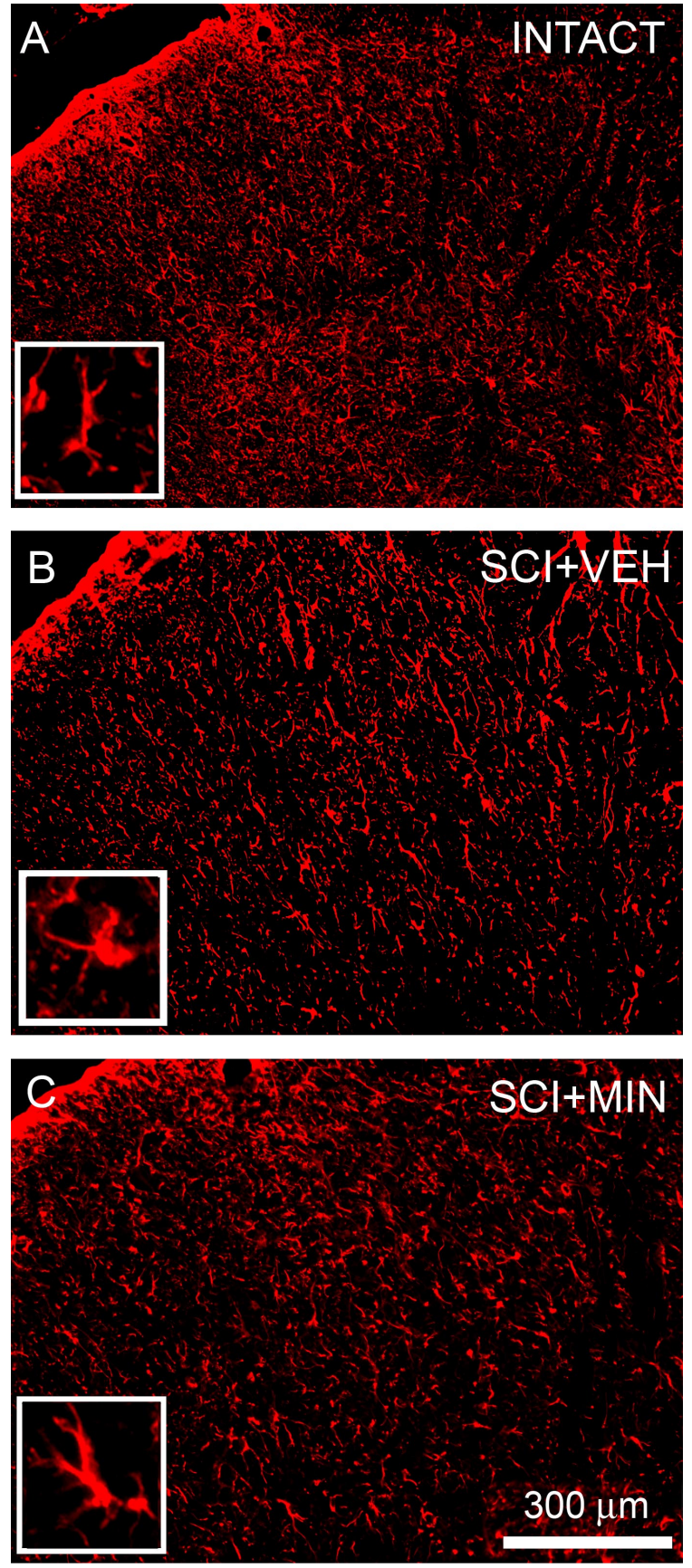

D

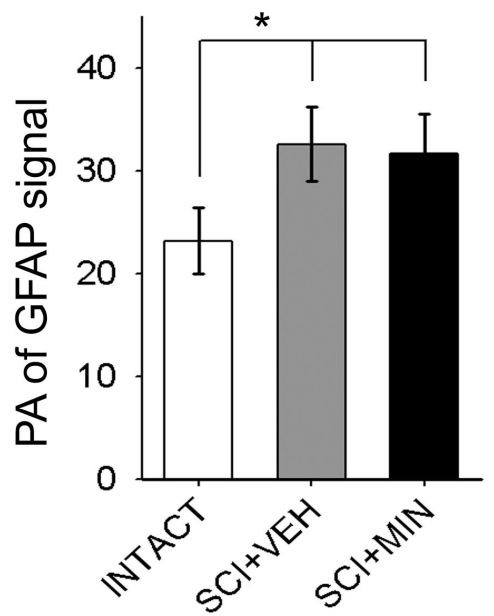

column on a stereotaxic apparatus (Kopf Instruments, Tujunga, CA). The exposed spinal cord was covered with warm $\left(37^{\circ} \mathrm{C}\right)$ mineral oil. Units were isolated from L3-L5 medially near the dorsal root entry zone up to a depth of $1000 \mu \mathrm{m}$. Recordings were made with a low-impedance $5 \mathrm{M} \Omega$ tungsten-insulated microelectrode (A-M Systems, Carlsborg, WA). Electrical signals were amplified and filtered at $300-3000 \mathrm{~Hz}$ (DAM80; World Precision Instruments, Sarasota, FL), processed by a data collection system (CED 1401+; Cambridge Instruments, Cambridge, UK), and stored on a computer (Latitude D800; Dell, Austin, TX). The stored digital record of individual unit activity was retrieved and analyzed off-line with Spike2 software (v5.03; Cambridge Electronic Design, Cambridge, UK).

After a cell was identified and its receptive field was mapped, natural stimuli were applied: (1) phasic brush (PB) stimulation of the skin with a cotton applicator; (2) stimulation with calibrated von Frey filaments of increasing force $(0.39,1.01$, and $20.8 \mathrm{~g})$; (3) compressive pressure, by attaching a large arterial clip with a weak grip to a fold of the skin (144 $\mathrm{g} / \mathrm{mm}^{2}$ ); and (4) compressive pinch, by applying a small arterial clip with a strong grip to a fold of skin $\left(583 \mathrm{~g} / \mathrm{mm}^{2}\right)$. Multireceptive neurons were identified by their relative magnitude of responsiveness to all stimuli. Because functional phenotype shifts can occur after SCI, such that more units assume a multireceptive functional classification, our search paradigm ensured that, in all groups, we sampled multireceptive units. Stimulation was applied with the experimenter blinded to the output of the cell during stimulation. Background activity was recorded for $20 \mathrm{~s}$, and stimuli were applied serially for $20 \mathrm{~s}$, separated by another $20 \mathrm{~s}$ of spontaneous activity without stimulation. Care was taken to ensure that the responses were maximal, that each stimulus was applied to the primary receptive field of the cell, and that isolated units remained intact for the duration of each experiment using Spike2 template-matching routines. Based on previously published statistical analysis of evoked discharge rates in intact control and SCI animals (Christensen and Hulsebosch, 1997; Hains et al., 2003a,b,c), neurons were considered to be hyperresponsive if evoked discharge rates were $>150 \%$ of control levels.

Behavioral testing. All behavioral testing was performed by a blinded observer. Testing began on day 28 after SCI to confirm that SCI animals had developed behavioral signs of chronic pain (for all experiments, we used only animals that demonstrated the development of chronic pain) before i.t. drug administration of either vehicle or minocycline. Daily testing resumed on day 30 after i.t. catheterization. Vehicle or minocycline was administered from days 31-33. Behavioral testing continued for two additional days until day 35 . On the first day of behavioral testing after SCI, motor performance of rats with SCI recovered well enough to yield reliable withdrawal reflex measures, as shown in previous studies (Hains et al., 2001).

Locomotor function was recorded using the Basso, Beattie, and Bresnahan (BBB) rating scale (Basso et al., 1995) to ensure reliability of hindlimb somatosensory testing, as well as to assess the motor effects of delivered compounds. Briefly, the BBB is a 21-point ordinal scale ranging from 0 , which is no discernable hindlimb movement, to 21 , which is consistent and coordinated gait with parallel paw placement of the hindlimb and consistent trunk stability. Scores from 0 to 7 rank the early phase of recovery with return of isolated movements of three joints (hip, knee, ankle); scores from 8 to 13 describe the intermediate recovery phase with return of paw placement, stepping, and forelimb-hindlimb coordi-

$\leftarrow$

Figure 1. Immunolabeling for normal and reactive astroglia. Basal levels of GFAP signa were observed within the lumbar dorsal horn of intact animals $(\boldsymbol{A})$. Higher magnification inset in $\boldsymbol{A}$ shows the typical resting astroglial morphology of long slender processes and small soma diameter. Distribution was uniform throughout white and gray matter. In SCl animals, on day 33 , after $3 \mathrm{~d}$ of i.t. administration of vehicle $(\mathrm{SCl}+\mathrm{VEH})$, astroglia assumed an activated phenotype ( $\boldsymbol{B})$, whereby they exhibited a swollen appearance ( $\boldsymbol{B}$, inset). In SCl animals, on day 33, after $3 \mathrm{~d}$ of i.t. administration of the microglial inhibitor minocycline $(\mathrm{SCl}+\mathrm{MIN})$, signal remained unchanged compared with SCI+VEH (C). Astroglial morphological resembling an activated phenotype is shown $(\boldsymbol{C}$, inset). The percentage of field analysis revealed significantly $\left({ }^{*} p<0.05\right)$ elevated levels of astroglial activation in $\mathrm{SCI}+\mathrm{VEH}$ and $\mathrm{SCI}+$ MIN groups, compared with intact animals $(\boldsymbol{D})$. Error bars represent mean \pm SD. 

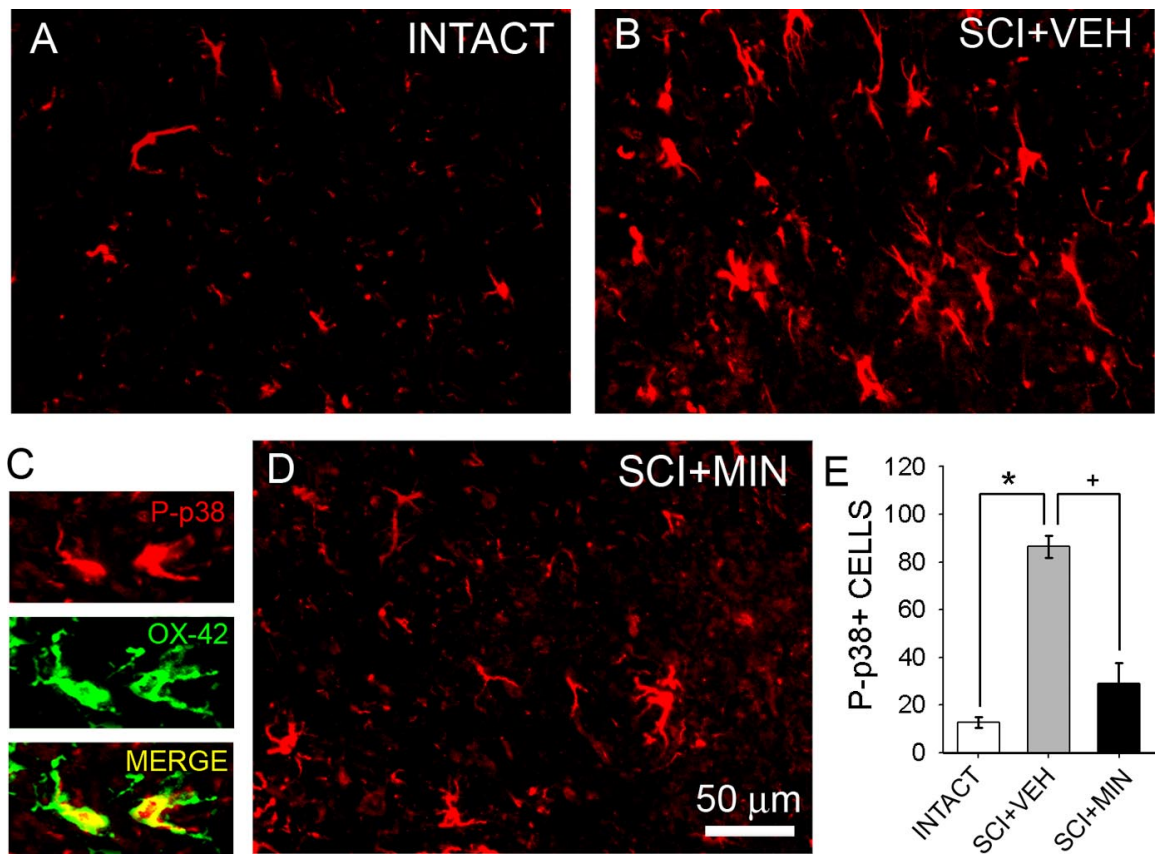

Figure 2. Immunolabeling for phosphorylated p-38MAP kinase. Low levels of P-p38 signal were detected in the lumbar dorsal horn of intact animals $(\boldsymbol{A})$. P-p38-positive cells exhibited a glial morphology with slender processes and were present primarily in gray matter. Thirty-three days after $\mathrm{SCl}$ and vehicle administration $(\mathrm{SCl}+\mathrm{VEH}), \mathrm{P}-\mathrm{p} 38$ signal was increased, and P-p38-positive cells were more numerous $(\boldsymbol{B})$. Positive cells exhibited morphological features of activated microglia: cell bodies were small, and several slender branched processes emerged from the soma. P-p38 (red) was colocalized to 0X-42-positive cells (green) after SCl (C). In SCl animals, minocycline delivered i.t. for $3 \mathrm{~d}(\mathrm{SCl}+\mathrm{MIN})$ resulted in a reduction in P-p38-positive cells (D). Morphological features of P-p38-positive cells were characteristic of quiescent microglia. Quantification revealed that after SCl, there was a significant $\left({ }^{*} p<0.05\right)$ increase in the number of P-p38-positive cells when compared with intact animals $(\boldsymbol{E})$. Compared with the $\mathrm{SCl}$ group, minocycline significantly $\left({ }^{+} p<0.05\right)$ reduced the number of P-p38-positive cells $(\boldsymbol{E})$. Error bars represent mean $\pm \mathrm{SD}$. nation; and scores from 14 to 21 rank the late phase of recovery with return of toe clearance during the step phase, predominant paw position, trunk stability, and tail position.

Mechanical nociceptive thresholds were determined by paw withdrawal to application of a series of calibrated von Frey filaments (Stoelting, Wood Dale, IL) to the glabrous surface of the hindpaws. Before testing, animals were acclimatized to the testing area for 30 min. After application of von Frey filaments $(0.4-26 \mathrm{~g})$ with enough force to cause buckling of the filament, a modification of the "updown" method of Dixon (1980) was used to determine the value at which paw withdrawal occurred $50 \%$ of the time (Chaplan et al., 1994), interpreted to be the mechanical nociceptive threshold.

After acclimation to the test chamber, thermal nociceptive thresholds were assessed by measuring the latency of paw withdrawal in response to a radiant heat source (Dirig et al., 1997). Animals were placed in Plexiglas boxes on an elevated glass plate $\left(37^{\circ} \mathrm{C}\right)$ under which a radiant heat source (5.14 amps) was applied to the glabrous surface of the paw through the glass plate. The heat source was turned off automatically by a photocell after limb-lift, allowing the measurement of paw withdrawal latency. If no response was detected, the heat source was automatically shut off at $20 \mathrm{~s}$. Three minutes were allowed between each trial, and four trials were averaged for each limb. Integrals were calculated from behavioral data and interpreted an indexed difference scores (Hua et al., 2005).

Statistical analysis. All statistical tests were performed at the $\alpha$ level of significance of 0.05 by two-tailed analyses using parametric tests. Data were tested for significance using one-way ANOVA, followed by Bonferroni post hoc analysis. Tests of factors including pair-wise comparisons were applied with either the paired Student's $t$ test or the two-sample Student's $t$ test. Data management and statistical analyses were performed using SAS (1992) statistical procedures with Jandel SigmaStat (v1.0) and graphed using Jandel SigmaPlot (v7.0) as mean \pm SD.

\section{Results}

Immunocytochemistry

Immunocytochemistry for detection of GFAP, a marker for normal as well as reactive astroglia, revealed that in intact animals, there was a baseline expression of GFAP in the lumbar enlargement (Fig. 1A). GFAP-positive astroglia demonstrated round nuclei and slender processes and were distributed throughout both white and gray matter. Within the gray matter, laminar expression was uniform. Thirty-three days after SCI, after vehicle treatment, astroglia assumed increased GFAP staining, a swollen hypertrophic appearance (Fig. $1 B$, inset) indicating an activated phenotype. On day 33, treatment of SCI animals with minocycline (Fig. 1C) had no effect on levels of astroglial morphology compared with vehicle. The percentage of field analysis revealed that in SCI animals receiving vehicle or minocycline, astroglial activation was significantly $(p<0.05)$ increased compared with intact animals (Fig. 1D).

P-p38 was observed in the intact spinal cord (Fig. 2A), but levels of signal were very low, as were the number of P-p38-positive cells (Fig. 2E). After SCI, however, there was a marked increase in P-p38 signal in all laminas within the lumbar dorsal horn (Fig. 2B). P-p38 is not a specific marker of, but has been associated with, microglial activation. P-p38 was colocalized to CD11b/c (OX42)-positive microglia (Fig. 2C) in $88 \%$ (44 of 50) of cells sampled in SCI animals. The majority of signal was observed in gray matter; however, a small degree of $\mathrm{P}$-p 38 signal was also observed within the white matter. P-p38-positive cells exhibited typical glia-like morphology; cell bodies were compact, and two to four slender branched processes emerged from each cell. The number of P-p38-positive cells was significantly $(p<0.05)$ higher in the SCI group when compared with intact (Fig. $2 E$ ). Treatment with minocycline (Fig. 2D) resulted in a significant (Fig. $2 E$ ) reduction in the number of P-p38-positive cells after injury.

Antibodies against OX-42 revealed moderate expression of resident microglia in both white and gray matter of intact spinal cord (Fig. $3 A$ ) exhibiting the quiescent or resting type morphology: small compact somata bearing many long thin ramified processes (Fig. 3A', $D^{\prime}$ ). After SCI (Fig. 3B), microglia exhibited an activated phenotype: marked cellular hypertrophy and retraction of cytoplasmic processes (Fig. 3D'). Compared with intact animals, SCI animals demonstrated a significant $(p<0.01)$ shift from resting to activated forms (determined by counting the number of cells with processes longer/shorter than the soma diameter) (Fig. 3D). In SCI animals, treatment with minocycline (Fig. $3 C$ ) resulted in a significant $(p<$ 0.01 ) reduction in the proportion of microglia demonstrating an activated phenotype (Fig. 3D).

\section{Extracellular unit recordings}

Dorsal horn multireceptive units were sampled in the lumbar enlargement in intact animals and after SCI and/or acute drug administration. In SCI animals, $30 \mathrm{~d}$ after injury, minocycline was 
administered and a time course of maximum efficacy for selected doses was determined (Fig. 4). Minocycline resulted in rapid depression of evoked response to noxious press stimuli. Discharge activity was significantly $(p<0.05)$ decreased within $10 \mathrm{~min}$, peaking at 25-45 min. By $60 \mathrm{~min}$ after application, evoked responses to press had returned to $90 \%$ of maximum predrug levels. After this period, the drug was washed out and responses returned to predrug levels by $75 \mathrm{~min}$.

Spontaneous background activity of multireceptive units after acute delivery of minocycline is shown for SCI animals in Figure 5. Administration of minocycline had no effect on ongoing activity over the course of $60 \mathrm{~min}$. Expansion of waveform traces is shown for periods corresponding to time of administration of drug, peak effectiveness of drug, and at the end of 60 min. At the time of administration of minocycline (Fig. 5, a1), mean spontaneous firing rate was $3.7 \pm 1.6 \mathrm{~Hz}$. At the peak effectiveness of minocycline (Fig. 5, a2), spontaneous activity was $3.5 \pm 1.8$ $\mathrm{Hz}$, and at $60 \mathrm{~min}$ (Fig. 5, a3), it was $4.5 \pm 2.0 \mathrm{~Hz}$.

Figure 6 shows the effects of acute administration of minocycline on peripherally evoked activity $30 \mathrm{~d}$ after SCI. A representative unit from an intact animal displaying evoked responses is shown (Fig. $6 A$ ) for comparison. After SCI (Fig. 6B), evoked responses were increased to all peripheral stimuli. Peristimulus time histograms show that after SCI, evoked discharge rates were between 40 and $100 \mathrm{~Hz}$. Phasic brush stimulation as well as compressive press and pinch stimuli resulted in high-frequency discharge. Von Frey filament stimulation resulted in graded increases in responsiveness of sampled units. Minocycline administration resulted in decreased evoked responses to all peripheral stimuli. Predrug unit responses are shown (Fig. 6B) and are overlaid on peak minocycline effects (Fig. 6C). Examples of unit activity to press stimulation for SCI (Fig. 6b1) and SCI plus minocycline (Fig. $6 c 1$ ) illustrate the effect of minocycline, which attenuated the post-SCI hyperresponsiveness. In SCI animals, minocycline significantly $(p<0.05)$ reduced the evoked responses to all peripheral stimuli (Fig. 6D).

To determine whether ongoing microglial activation contributes to hyperresponsiveness of dorsal horn neurons, we also examined evoked activity after minocycline administration (for $3 \mathrm{~d}$ ) had stopped. Evoked activity of representative multireceptive units is shown $1 \mathrm{~d}$ after cessation of minocycline administration to SCI animals (Fig. 7). After administration of minocy-

INTACT
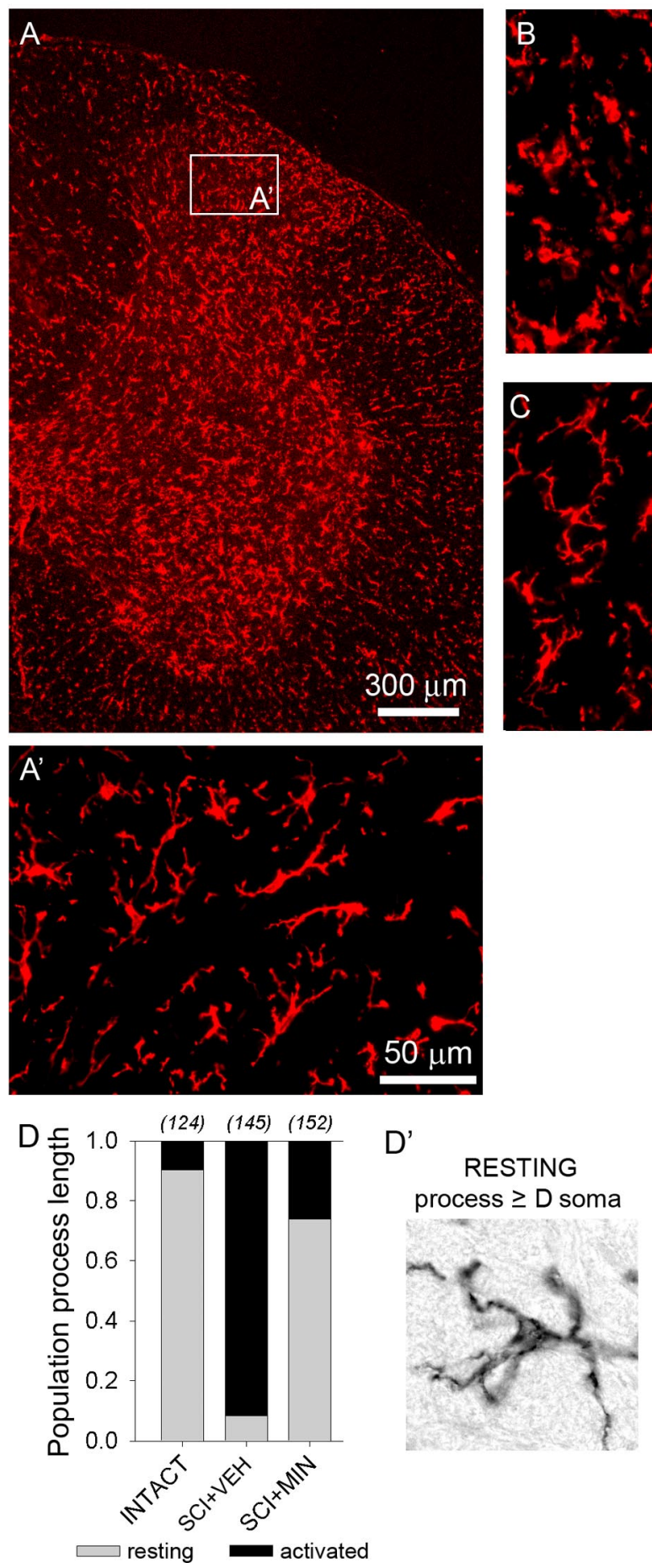

Figure 3. Immunolabeling for $0 \mathrm{X}-42$-positive microglia. $0 \mathrm{X}-42$ signal revealed moderate expression of resident microglia in both white and gray matter of the lumbar dorsal horn in an intact spinal cord $(\boldsymbol{A})$. Microglia exhibited the resting type morphology: small compact somata bearing long, thin, ramified processes $(\boldsymbol{A})$. Thirty-three days after $\mathrm{SCl}$, in vehicle-treated animals $(\mathrm{SCl}+\mathrm{VEH})$, microglia exhibited the activated phenotype: marked cellular hypertrophy and retraction of processes $(\boldsymbol{B})$. Very few cells exhibiting resting morphological features were detected. In SCl animals, on day 33, after 3 d of i.t. administration of minocycline (SCI+MIN), microglia assumed the resting morphology (C). Quantification $(\boldsymbol{D})$ of the proportion of resting $\left(\boldsymbol{D}^{\prime}\right)$ and activated $\left(\boldsymbol{D}^{\prime \prime}\right)$ microglia confirmed that after $\mathbf{S C l}$, there is a large shift from resting to activated microglia and that minocycline significantly reversed this shift.
$\mathrm{SCl}$
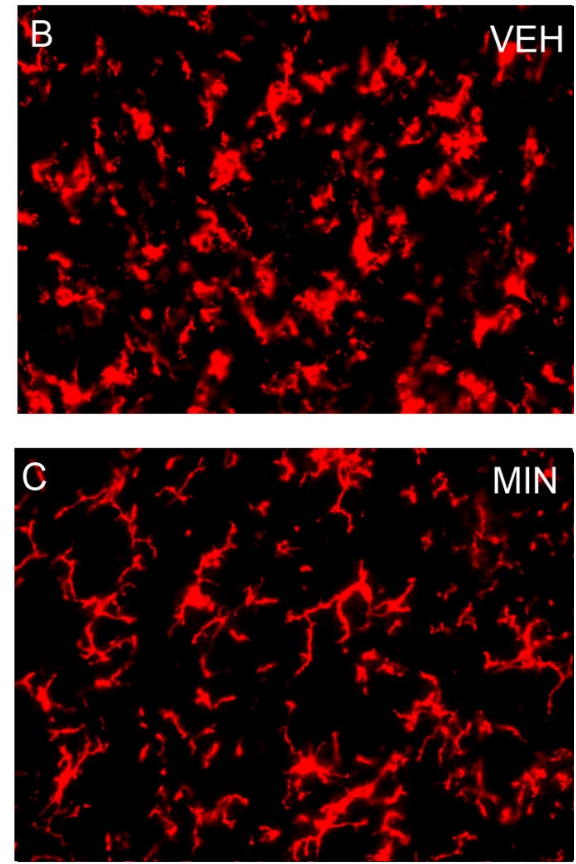

$D^{\prime \prime}$

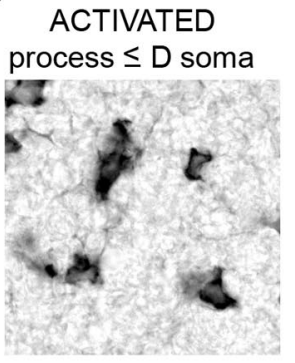

cline was discontinued (Fig. 7A), evoked responses to peripheral stimulation were increased. Quantification of responses to each stimulus revealed no differences between SCI or SCI animals after cessation of minocycline treatment (Fig. 7B). 


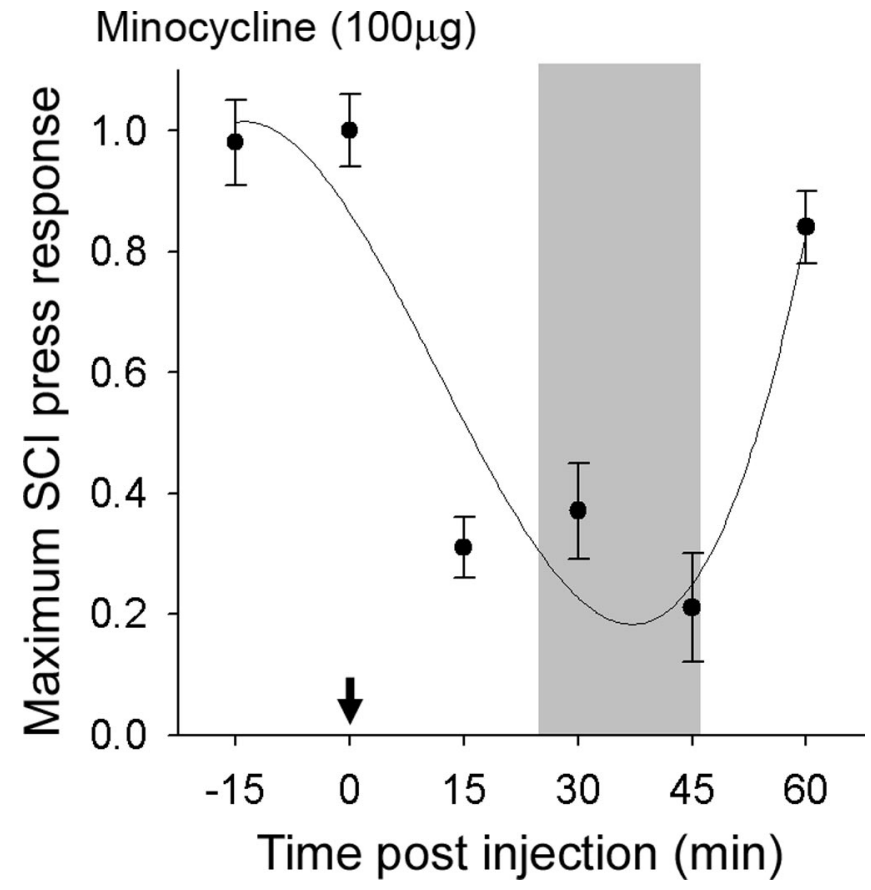

Figure 4. Thirty days after $\mathrm{SCl}$, dorsal horn multireceptive units were sampled from the lumbar enlargement of $\mathrm{SCl}$ animals after acute topical administration of minocycline (arrow). The time course for maximum depression of evoked response to press stimulation of a receptive field located on the hindpaw after administration of minocycline revealed peak efficacy at 25-45 min for $100 \mu \mathrm{g}$. For subsequent electrophysiological experiments, units were sampled at time points of peak efficacy (shaded region).

\section{Behavioral testing}

Intact animals demonstrated expected levels of locomotor function (group mean, $21.0 \pm 0.0$ ), mechanical nociceptive threshold (group mean, $19.9 \pm 2.1 \mathrm{~g}$ ), and thermal paw withdrawal latency (group mean, $10.6 \pm 0.5 \mathrm{~s}$ ). For testing of the behavioral effects of microglia-acting compounds, on day 28 , SCI animals were divided randomly into either vehicle or minocycline groups; before drug administration, the groups were matched and did not differ significantly in terms of BBB scores, mechanical thresholds, or thermal paw withdrawal latencies.

Thirty days after SCI, BBB scores had significantly increased relative to acute postinjury values and reached a plateau at a mean value of $10.4 \pm 2.1$. Three days after the start of vehicle or minocycline injections (day 33), BBB scores remained unchanged in all groups (Fig. $8 \mathrm{~A}$ ) from day 30; scores were $10.1 \pm 2.0$ and $11.9 \pm$ 2.6, for SCI groups treated with vehicle and minocycline, respectively. On day 35, there were no significantly differences in BBB score.

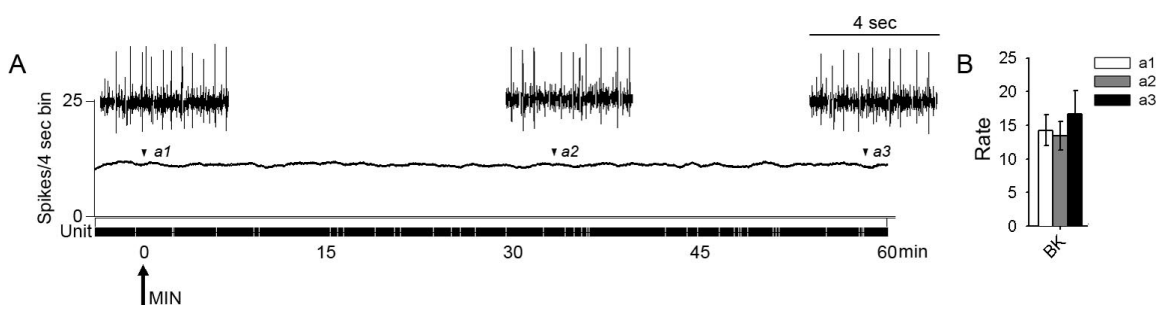

Figure 5. Spontaneous background activity of lumbar dorsal horn multireceptive units was recorded in $\mathrm{SCl}$ animals $30 \mathrm{~d}$ after injury, after acute spinal administration of minocycline $(\boldsymbol{A}$, arrow). Minocycline had no effect on ongoing activity over the course of $60 \mathrm{~min}$. Expansion of waveform traces is shown for periods corresponding to time of minocycline administration (a1), peak effectiveness of drug (a2) (Fig. 4), and at the end of $60 \mathrm{~min}(\boldsymbol{a} 3)$. Quantification (B) of mean spontaneous firing revealed no significant differences at any point in response to minocycline (bin width, 4 s). Error bars represent mean \pm SD. BK, Background.
After SCI, mechanical paw withdrawal thresholds had significantly $(p<0.05)$ decreased in all groups (group mean, $3.9 \pm$ $1.5 \mathrm{~g})$ compared with intact animals. Administration of minocycline had an immediate effect on mechanical thresholds and reversed decreases that occurred after SCI (range, $7.9 \pm 1.5$ to $14.2 \pm 2.0$ ) (Fig. 8 B). Immediately after cessation of minocycline, mechanical thresholds returned to predrug levels and were equivalent to untreated animals $(3.9 \pm 1.8 \mathrm{~g})$.

Thermal paw withdrawal latencies (Fig. $8 C$ ) for all groups were significantly $(p<0.05)$ lowered after SCI to a group mean of $5.8 \pm 2.1 \mathrm{~s}$. Minocycline resulted in an immediate increase in paw withdrawal latencies $(11.1 \pm 1.7 \mathrm{~s})$ on the first day of delivery. Minocycline continued to be effective in increasing latencies for the duration of administration. After cessation of delivery, latencies returned to predrug levels $(5.6 \pm 0.9 \mathrm{~s})$, which persisted for the duration of the experiment.

Difference index, as measured by integral analysis (Fig. 8D), revealed that BBB scores were equivalent in SCI and treatment groups. Integrated differences revealed that minocycline resulted in a more robust modulation of mechanical nociception compared with thermal nociception.

\section{Discussion}

In this study, we show that there is a large shift in microglial status from a resting state to an activated state in the lumbar dorsal horn after SCI. Because these results suggest an association between microglial activation, which is known to contribute to pain after peripheral nerve injury, and hyperresponsiveness of dorsal horn neurons to peripheral stimulation and chronic pain after SCI, we pharmacologically downregulated the activity of microglia with the inhibitor minocycline. After acute delivery of minocycline, we showed a return to resting morphological phenotype as well as reductions in electrophysiologic and behavioral concomitants of pain, suggesting a role of microglia in the active modulation of ongoing below-level pain after SCI.

The precise role of activated microglia in chronic pain has not been studied previously, and our finding of a contribution of activated microglia to maintaining chronic pain after SCI is novel in several ways. There is a body of literature that suggests that microglia are involved in the initial phase of development of chronic pain after peripheral injury, but the role of microglia in its ongoing maintenance of pain has not been reported. For example, in the L5 spinal nerve transection model, minocycline administered preemptively at the time of injury reverses hyperalgesia and allodynia, presumably because of its ability to suppress microglial activation; but initiation of minocycline treatment $5 \mathrm{~d}$ after transection fails to attenuate allodynia and hyperalgesia, although it does inhibit microglial activation (Raghavendra et al., 2003). Similarly, minocycline has no effect on phase two of formalin-induced flinching or carrageenan-induced hyperalgesia (Hua et al., 2005). Ledeboer et al. (2005) reported that minocycline is effective in delaying the induction of allodynia after sciatic nerve inflammation but not in its attenuation 1 week after onset. Interestingly, in a model of centrally mediated hyperalgesia induced by i.t. NMDA, minocycline does effectively reduce acute pain (Hua et al., 2005).

Our findings also demonstrate that microglia actively contribute to neuronal hy- 

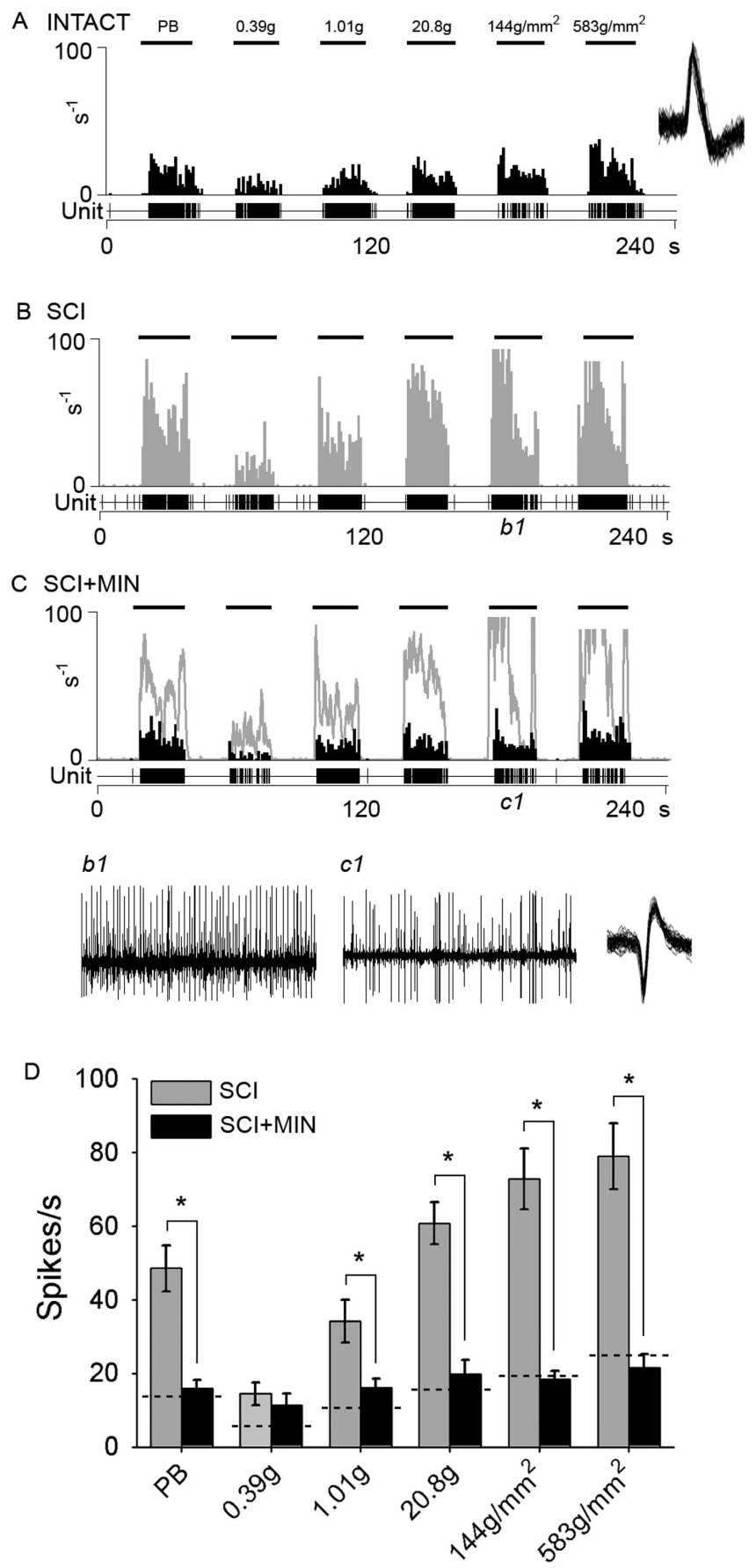

Figure 6. The effects of acutely administered minocycline on peripherally evoked activity in multireceptive units from $\mathrm{SCl}$ animals $30 \mathrm{~d}$ after injury. A representative unit from an intact animal displaying evoked responses to natural stimuli (PB, $0.39 \mathrm{~g}, 1.01 \mathrm{~g}, 20.8 \mathrm{~g}, 144 \mathrm{~g} / \mathrm{mm}^{2}$, and $583 \mathrm{~g} / \mathrm{mm}^{2}$ refer to phasic brush, von Frey filaments of increasing intensities, pressure, and pinch, applied for $20 \mathrm{~s}$ ) is shown for comparison (A). The peristimulus time histogram shows that after SCl, evoked responses were increased to all peripheral stimuli (B). After SCl, evoked discharge rates were between 40 and $100 \mathrm{~Hz}$. Phasic brush stimulation as well as compressive press and pinch stimuli resulted in high-frequency discharge. Von Frey filament stimulation resulted in graded increases in responsiveness of sampled units. At 30 min after administration, minocycline $(\mathrm{SCl}+\mathrm{MIN})$ resulted in decreased evoked responses to all peripheral stimuli $(\boldsymbol{C})$. Predrug unit responses are overlaid on the $\mathrm{SCl}+\mathrm{MIN}$ histogram. Example waveform of unit activity to press stimulation for $\mathrm{SCl}(\boldsymbol{b} \mathbf{1})$ and $\mathrm{SCl}+\mathrm{MIN}$ ( $\boldsymbol{c}$ ) illustrate the effect of minocycline, which attenuated the post-SCI hyperresponsiveness. Minocycline significantly $\left({ }^{*} p<0.05\right.$ ) reduced the evoked responses to all peripheral stimuli after $S C(D)$. Dashed lines indicated mean responses of intact animals. Error bars represent mean $\pm S D$.
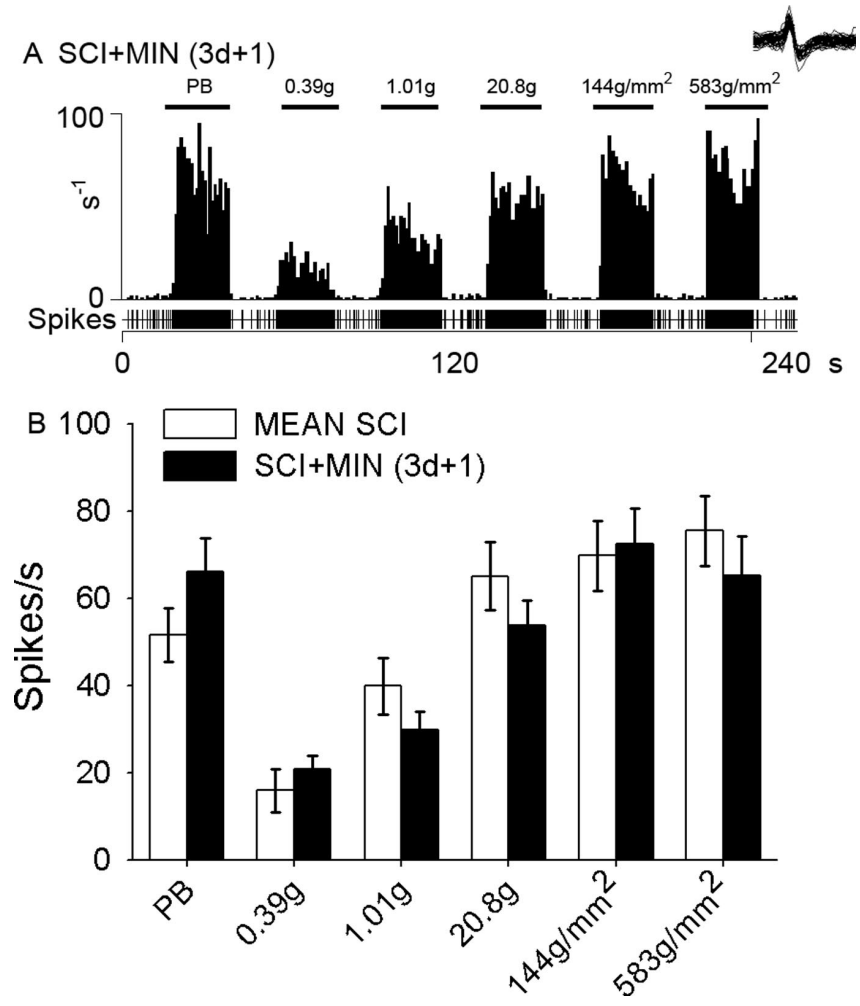

Figure 7. Evoked activity of a representative multireceptive unit $1 \mathrm{~d}$ after cessation of i.t.delivered (3 din duration) minocycline after $\mathrm{SCl}(\mathrm{SCl}+\mathrm{MIN})$. After discontinuation of minocycline administration, evoked responses to peripheral stimulation ( $P B, 0.39 \mathrm{~g}, 1.01 \mathrm{~g}, 20.8 \mathrm{~g}, 144$ $\mathrm{g} / \mathrm{mm}^{2}$, and $583 \mathrm{~g} / \mathrm{mm}^{2}$ refer to phasic brush, von Frey filaments of increasing intensities, pressure, and pinch, applied for $20 \mathrm{~s}$ ) were elevated, indicating hyperresponsiveness ( $\boldsymbol{A}$ ). Quantification of responses to each stimulus revealed no significant differences between $\mathrm{SCl}$ and $\mathrm{SCl}$ animals after cessation of minocycline $(\boldsymbol{B})$. Error bars represent mean \pm SD.

perresponsiveness and pain-related behaviors even after transient reversion to a resting phenotype; inhibition with minocycline produced only a temporary reduction in high evoked responses of dorsal horn neurons and an elevation of behavioral pain thresholds after SCI. Immediately after withdrawal of minocycline, there was a return to predrug pain levels. This is a different mode of action for microglia in central pain compared with peripheral pain. Chronic pain after peripheral injury is thought to be mediated by a microglia $\rightarrow$ astroglia replacement mechanism.

Reactive astrogliosis is known to participate in scar formation and genesis of a regenerative barrier after SCI (Silver and Miller, 2004), the elimination of which can lead to improvements in neuromotor function (Menet et al., 2003; Okada et al., 2004). Recently, it has been suggested that astroglia may be involved in at-level pain after SCI (Nesic et al., 2005). In models of peripheral injury, it has been similarly suggested that astroglia are involved in chronic pain (Garrison et al., 1991; Ji and Strichartz, 2004), purportedly through a mechanism by which astrocytes replace activated microglia to sustain synaptic changes configured by previously activated microglia (Tanga et al., 2004). Levels of astroglial activation appear to be closely correlated with pain behaviors in some models (Coyle, 1998; Raghavendra et al., 2003). The ineffectiveness of minocycline in modulating pain in peripheral models can be explained by this mechanism (Raghavendra et al., 2003), although it should be noted that this hypothesis remains speculative (Stuesse et al., 2001; Winkelstein and DeLeo, 2002). Our data, however, do not provide support to this pur- 

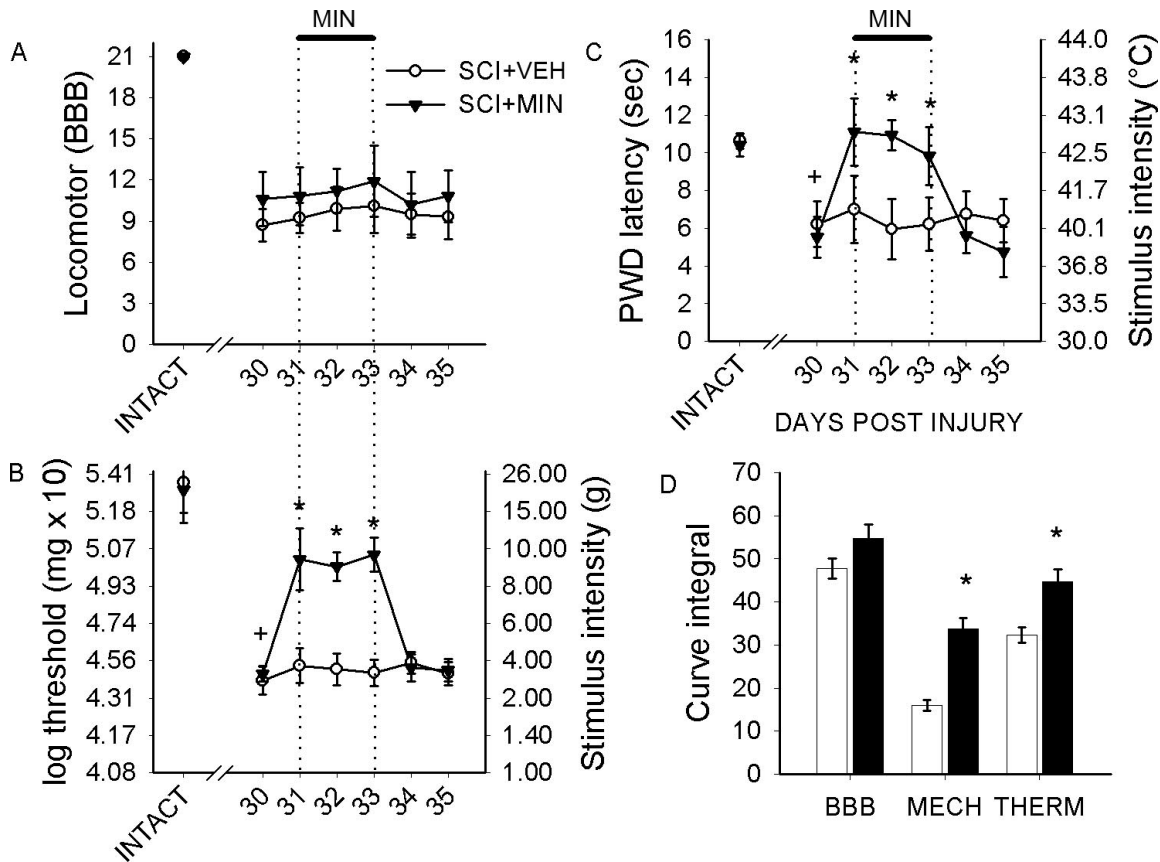

Figure 8. Behavioral analysis of locomotor function and pain-related behaviors. Intact animals demonstrated expected levels of locomotor function, but $30 \mathrm{~d}$ after $\mathrm{SCl}, \mathrm{BBB}$ scores revealed partial recovery of locomotor function for injured animals $(\boldsymbol{A})$. In $\mathrm{SCl}$ animals, i.t. delivery of vehicle (SCI+VEH) or minocycline (SCI+MIN) had no significant effect during the period of administration (indicated by thick line) or for $2 \mathrm{~d}$ after cessation of administration, indicating no activation or depression of motor function that could compromise testing of nociceptive thresholds. After $\mathrm{SCl}$, mechanical paw withdrawal thresholds had significantly $\left({ }^{+} p<\right.$ 0.05 ) decreased in all groups when compared with intact animals $(\boldsymbol{B})$. Minocycline resulted in an immediate increase in mechanical thresholds for the duration of administration. This effect was significant $\left({ }^{*} p<0.05\right)$. Immediately after cessation of administration (day 33), mechanical thresholds returned to predrug levels that were equivalent to untreated SCl animals. Thermal paw withdrawal latencies $(\boldsymbol{C})$ were significantly $\left({ }^{+} p<0.05\right)$ lowered after $\mathrm{SCl}$. Minocycline resulted in an immediate and significant $\left({ }^{*} p<0.05\right)$ increase in paw withdrawal latencies. Minocycline sustained increased latencies for the duration of its administration. After cessation of delivery, latencies returned to predrug levels, which persisted for the duration of the experiment. Integral analysis $(\boldsymbol{D})$ revealed that minocycline resulted in a significantly $\left({ }^{*} p<0.05\right)$ more robust modulation of mechanical nociception compared with thermal nociception. Error bars represent mean \pm SD. sec, Seconds.

ported microglia replacement role for astroglia in post-SCI pain. Although other results clearly demonstrate astroglial activation after SCI, we do not see evidence of morphological alterations after inhibition of microglial activation with minocycline [which does not affect astroglia or neurons (Zhang et al., 2003)]. The available evidence suggests that there is a need to better understand their respective contributions. For now, the most conservative conclusion is that peripheral and central injuries produce unique microglial and astroglial pathologies that contribute in different ways to pain phenomena. Furthermore, it may be that central injury results in an even more complex microglial response than peripheral injury; in spinal cord transection and compression models, there are time- and location-dependent variations in microglial activation (Watanabe et al., 1999).

In models of pain after peripheral injury, there is evidence that p38 microtubule-associated protein (MAP) kinase is phosphorylated (P-p38) and rendered active in association with microglial activation (Kim et al., 2002; Obata et al., 2004; Tsuda et al., 2004). P-p38 is localized within hypertrophic spinal microglia in the dorsal horn (Kim et al., 2002; Hua et al., 2005) and DRG neurons (Ji et al., 2002; Kim et al., 2002), although its precise role in activation of microglia remains uncertain. Others have shown p38 phosphorylation after SCI (Nakahara et al., 1999; Wang et al., 2005; Crown et al., 2006), and that minocycline improves outcome after SCI, possibly through the inhibition of p38 MAP kinase signaling pathways (Wells et al., 2003; Stirling et al., 2004,
2005). Our data implicate P-p38 in chronic pain phenomena after SCI. We demonstrate that $\mathrm{P}-\mathrm{p} 38$ upregulation is concomitant with the activation of microglia within the lumbar dorsal horn. It has been proposed that peripheral nerve injury can trigger a p38-dependent activation of spinal microglia that contribute to pain and, with time, a further activation of astroglia, and that this may also contribute to pain associated with SCI (McMahon et al., 2005). Our data partially support this hypothesis.

It is known that after activation, microglia release excitatory amino acids (Hua et al., 1999), interleukin-1 $\beta$ (Ferrari et al., 1997), and prostaglandin E2 (Svensson et al., 2003), which have been implicated in the induction of central sensitization of spinal neurons (Palecek et al., 1994; Minami et al., 1999; Samad et al., 2001; Ji et al., 2003). Microglia may therefore actively participate in the generation of central sensitization after SCI. Conversely, ATP (Hu et al., 2002; Chiang et al., 2005), substance P (Xu et al., 1992; Afrah et al., 2002), and glutamate (Sluka and Westlund, 1993) are released in high amounts during central sensitization and participate in its induction and might activate microglia (Giulian et al., 1996; Svensson et al., 2003; Tsuda et al., 2003), so that the sensitization of dorsal horn neurons may also stimulate microglia, which become further activated, establishing a feedforward cycle. This may offer an explanation of the susceptibility of microglia and pain-related behaviors to minocycline at chronic time points, weeks after injury and the onset of pain behavior, in our central injury paradigm.

These data implicate microglia in below-level chronic central pain after SCI. Our results demonstrate that SCI can dramatically induce the activation of microglia in the lumbar dorsal horn and show that this microglial activation contributes to neuronal hyperresponsiveness and alterations in behavioral pain thresholds. The unexpected finding that microglia are actively involved in ongoing pain phenomenology after SCI suggests significant differences from peripheral injury in which microglial activation seems to be related to the induction phase of pain. Future experiments should examine the role of microglia in the induction of chronic pain after SCI. The differential role of microglia in peripheral versus central injury also merits additional study. Additionally, given its ease of passage through the blood-brain barrier, low incidence of adverse effects in clinical studies, and effectiveness in a number of animal models of neurological disease, minocycline is emerging as a promising candidate therapy (Yong et al., 2004). Its clinical usefulness is currently being evaluated in Huntington's disease (Huntington Study Group, 2004), amyotrophic lateral sclerosis (Gordon et al., 2004), and multiple sclerosis (Metz et al., 2004). With interest growing over its possible usefulness in neuroprotection after SCI (Fehlings and Baptiste, 2005), our data suggest that minocycline may merit addi- 
tional study as a possible therapeutic agent for the treatment of post-SCI pain.

\section{References}

Afrah AW, Fiska A, Gjerstad J, Gustafsson H, Tjolsen A, Olgart L, Stiller CO, Hole K, Brodin E (2002) Spinal substance P release in vivo during the induction of long-term potentiation in dorsal horn neurons. Pain 96:49-55.

Attal N, Guirimand F, Brasseur L, Gaude V, Chauvin M, Bouhassira D (2002) Effects of IV morphine in central pain: a randomized placebocontrolled study. Neurology 58:554-563.

Basso DM, Beattie MS, Bresnahan JC (1995) A sensitive and reliable locomotor rating scale for open field testing in rats. J Neurotrauma 12:1-21.

Cardenas DD, Warms CA, Turner JA, Marshall H, Brooke MM, Loeser JD (2002) Efficacy of amitriptyline for relief of pain in spinal cord injury: results of a randomized controlled trial. Pain 96:365-373.

Chaplan SR, Bach FW, Pogrel JW, Chung JM, Yaksh TL (1994) Quantitative assessment of tactile allodynia in the rat paw. J Neurosci Methods 53:55-63.

Chiang CY, Zhang S, Xie YF, Hu JW, Dostrovsky JO, Salter MW, Sessle BJ (2005) Endogenous ATP involvement in mustard-oil-induced central sensitization in trigeminal subnucleus caudalis (medullary dorsal horn). J Neurophysiol 94:1751-1760.

Christensen MD, Hulsebosch CE (1997) Chronic central pain after spinal cord injury. J Neurotrauma 14:517-537.

Coyle DE (1998) Partial peripheral nerve injury leads to activation of astroglia and microglia which parallels the development of allodynic behavior. Glia 23:75-83.

Crown ED, Ye Z, Johnson KM, Xu GY, McAdoo DJ, Hulsebosch CE (2006) Increases in the activated forms of ERK 1/2, p38 MAPK, and CREB are correlated with the expression of at-level mechanical allodynia following spinal cord injury. Exp Neurol, in press.

Davidoff G, Guarracini M, Roth E, Sliwa J, Yarkony G (1987) Trazodone hydrochloride in the treatment of dysesthetic pain in traumatic myelopathy: a randomized, double-blind, placebo-controlled study. Pain 29:151-161.

Dirig DM, Salami A, Rathbun ML, Ozaki GT, Yaksh TL (1997) Characterization of variables defining hindpaw withdrawal latency evoked by radiant thermal stimuli. J Neurosci Methods 76:183-191.

Dixon WJ (1980) Efficient analysis of experimental observations. Annu Rev Pharmacol Toxicol 20:441-462.

Fehlings MG, Baptiste DC (2005) Current status of clinical trials for acute spinal cord injury. Injury 36:B113-B122.

Ferrari D, Chiozzi P, Falzoni S, Dal Susino M, Melchiorri L, Baricordi OR, Di Virgilio F (1997) Extracellular ATP triggers IL-1 beta release by activating the purinergic P2Z receptor of human macrophages. J Immunol 159:1451-1458

Finnerup NB, Jensen TS (2004) Spinal cord injury pain-mechanisms and treatment. Eur J Neurol 11:73-82.

Finnerup NB, Sindrup SH, Bach FW, Johannesen IL, Jensen TS (2002) Lamotrigine in spinal cord injury pain: a randomized controlled trial. Pain 96:375-383.

Finnerup NB, Biering-Sorensen F, Johannesen IL, Terkelsen AJ, Juhl GI, Kristensen AD, Sindrup SH, Bach FW, Jensen TS (2005) Intravenous lidocaine relieves spinal cord injury pain: a randomized controlled trial. Anesthesiology 102:1023-1030.

Fu KY, Light AR, Matsushima GK, Maixner W (1999) Microglial reactions after subcutaneous formalin injection into the rat hind paw. Brain Res 825:59-67.

Garrison CJ, Dougherty PM, Kajander KC, Carlton SM (1991) Staining of glial fibrillary acidic protein (GFAP) in lumbar spinal cord increases following a sciatic nerve constriction injury. Brain Res 565:1-7.

Giulian D, Corpuz M, Richmond B, Wendt E, Hall ER (1996) Activated microglia are the principal glial source of thromboxane in the central nervous system. Neurochem Int 29:65-76.

Gordon PH, Moore DH, Gelinas DF, Qualls C, Meister ME, Werner J, Mendoza M, Mass J, Kushner G, Miller RG (2004) Placebo-controlled phase I/II studies of minocycline in amyotrophic lateral sclerosis. Neurology 62:1845-1847.

Gruner JA (1992) A monitored contusion model of spinal cord injury in the rat. J Neurotrauma 9:123-126.

Hains BC, Yucra JA, Hulsebosch CE (2001) Reduction of pathological and behavioral deficits following spinal cord contusion injury with the selective cyclooxygenase-2 inhibitor NS-398. J Neurotrauma 18:409-423.

Hains BC, Willis WD, Hulsebosch CE (2003a) Serotonin receptors 5-HT1A and 5-HT3 reduce hyperexcitability of dorsal horn neurons after chronic spinal cord hemisection injury in rat. Exp Brain Res 149:174-186.

Hains BC, Klein JP, Saab CY, Craner MJ, Black JA, Waxman SG (2003b) Upregulation of sodium channel Nav1.3 and functional involvement in neuronal hyperexcitability associated with central neuropathic pain after spinal cord injury. J Neurosci 23:8881-8892.

Hains BC, Johnson KM, Eaton MJ, Willis WD, Hulsebosch CE (2003c) Serotonergic neural precursor cell grafts attenuate bilateral hyperexcitability of dorsal horn neurons after spinal hemisection in rat. Neuroscience 116:1097-1110.

Hains BC, Saab CY, Waxman SG (2005) Changes in electrophysiological properties and sodium channel Nav1.3 expression in thalamic neurons after spinal cord injury. Brain 128:2359-2371.

Hu B, Chiang CY, Hu JW, Dostrovsky JO, Sessle BJ (2002) P2X receptors in trigeminal subnucleus caudalis modulate central sensitization in trigeminal subnucleus oralis. J Neurophysiol 88:1614-1624.

Hua XY, Chen P, Marsala M, Yaksh TL (1999) Intrathecal substance P-induced thermal hyperalgesia and spinal release of prostaglandin E2 and amino acids. Neuroscience 89:525-534.

Hua XY, Svensson CI, Matsui T, Fitzsimmons B, Yaksh TL, Webb M (2005) Intrathecal minocycline attenuates peripheral inflammation-induced hyperalgesia by inhibiting p38 MAPK in spinal microglia. Eur J Neurosci 22:2431-2440.

Hulsebosch CE (2005) From discovery to clinical trials: treatment strategies for central neuropathic pain after spinal cord injury. Curr Pharm Des 11:1411-1420.

Huntington Study Group (2004) Minocycline safety and tolerability in Huntington disease. Neurology 63:547-549.

Ji RR, Strichartz G (2004) Cell signaling and the genesis of neuropathic pain. Science STKE 252:re14.

Ji RR, Samad TA, Jin SX, Schmoll R, Woolf CJ (2002) p38 MAPK activation by NGF in primary sensory neurons after inflammation increases TRPV1 levels and maintains heat hyperalgesia. Neuron 36:57-68.

Ji RR, Kohno T, Moore KA, Woolf CJ (2003) Central sensitization and LTP: do pain and memory share similar mechanisms? Trends Neurosci 26:696-705.

Jin SX, Zhuang ZY, Woolf CJ, Ji RR (2003) p38 mitogen-activated protein kinase is activated after a spinal nerve ligation in spinal cord microglia and dorsal root ganglion neurons and contributes to the generation of neuropathic pain. J Neurosci 23:4017-4022.

Kigerl KA, McGaughy VM, Popovich PG (2006) Comparative analysis of lesion development and intraspinal inflammation in four strains of mice following spinal contusion injury. J Comp Neurol 494:578-594.

Kim SY, Bae JC, Kim JY, Lee HL, Lee KM, Kim DS, Cho HJ (2002) Activation of p38 MAP kinase in the rat dorsal root ganglia and spinal cord following peripheral inflammation and nerve injury. NeuroReport 13:2483-2486.

Ledeboer A, Sloane EM, Milligan ED, Frank MG, Mahony JH, Maier SF, Watkins LR (2005) Minocycline attenuates mechanical allodynia and proinflammatory cytokine expression in rat models of pain facilitation. Pain 115:71-83.

Lee SM, Yune TY, Kim SJ, Park do W, Lee YK, Kim YC, Oh YJ, Markelonis GJ, Oh TH (2003) Minocycline reduces cell death and improves functional recovery after traumatic spinal cord injury in the rat. J Neurotrauma 20:1017-1027.

Loubser PG, Donovan WH (1991) Diagnostic spinal anaesthesia in chronic spinal cord injury pain. Paraplegia 29:25-36.

McMahon SB, Cafferty WB, Marchand F (2005) Immune and glial cell factors as pain mediators and modulators. Exp Neurol 192:444-462.

Menet V, Prieto M, Privat A, Gimenez y Ribotta M (2003) Axonal plasticity and functional recovery after spinal cord injury in mice deficient in both glial fibrillary acidic protein and vimentin genes. Proc Natl Acad Sci USA 100:8999-9004.

Metz LM, Zhang Y, Yeung M, Patry DG, Bell RB, Stoian CA, Yong VW, Patten SB, Duquette P, Antel JP, Mitchell JR (2004) Minocycline reduces gadolinium-enhancing magnetic resonance imaging lesions in multiple sclerosis. Ann Neurol 55:756.

Milligan ED, Zapata V, Chacur M, Schoeniger D, Biedenkapp J, O'Connor 
KA, Verge GM, Chapman G, Green P, Foster AC, Naeve GS, Maier SF, Watkins LR (2004) Evidence that exogenous and endogenous fractalkine can induce spinal nociceptive facilitation in rats. Eur J Neurosci 20:2294-2302.

Minami T, Okuda-Ashitaka E, Hori Y, Sakuma S, Sugimoto T, Sakimura K, Mishina M, Ito S (1999) Involvement of primary afferent C-fibres in touch-evoked pain (allodynia) induced by prostaglandin E2. Eur J Neurosci 11:1849-1856.

Nakahara S, Yone K, Sakou T, Wada S, Nagamine T, Niiyama T, Ichijo H (1999) Induction of apoptosis signal regulating kinase 1 (ASK1) after spinal cord injury in rats: possible involvement of ASK1-JNK and -p38 pathways in neuronal apoptosis. J Neuropathol Exp Neurol 58:442-550.

Nesic O, Lee J, Johnson KM, Ye Z, Xu GY, Unabia GC, Wood TG, McAdoo DJ, Westlund KN, Hulsebosch CE, Perez-Polo JR (2005) Transcriptional profiling of spinal cord injury-induced central neuropathic pain. J Neurochem 95:998-1014.

Obata K, Yamanaka H, Kobayashi K, Dai Y, Mizushima T, Katsura H, Fukuoka T, Tokunaga A, Noguchi K (2004) Role of mitogen-activated protein kinase activation in injured and intact primary afferent neurons for mechanical and heat hypersensitivity after spinal nerve ligation. J Neurosci 24:10211-10222.

Okada S, Nakamura M, Mikami Y, Shimazaki T, Mihara M, Ohsugi Y, Iwamoto Y, Yoshizaki K, Kishimoto T, Toyama Y, Okano H (2004) Blockade of interleukin- 6 receptor suppresses reactive astrogliosis and ameliorates functional recovery in experimental spinal cord injury. J Neurosci Res 76:265-276.

Popovich PG, Wei P, Stokes BT (1997) Cellular inflammatory response after spinal cord injury in Sprague-Dawley and Lewis rats. J Comp Neurol 377:443-464.

Qin C, Chandler MJ, Miller KE, Foreman RD (1999) Chemical activation of cervical cell bodies: effects on responses to colorectal distension in lumbosacral spinal cord of rats. J Neurophysiol 82:3423-3433.

Raghavendra V, Tanga F, DeLeo JA (2003) Inhibition of microglial activation attenuates the development but not existing hypersensitivity in a rat model of neuropathy. J Pharmacol Exp Ther 306:624-630.

Samad TA, Moore KA, Sapirstein A, Billet S, Allchorne A, Poole S, Bonventre JV, Woolf CJ (2001) Interleukin-1beta-mediated induction of Cox-2 in the CNS contributes to inflammatory pain hypersensitivity. Nature 410:471-475.

Siddall PJ, Molloy AR, Walker S, Rutkowski SB (2000) The efficacy of intrathecal morphine and clonidine in the treatment of pain after spinal cord injury. Anesth Analg 91:1-6.

Silver J, Miller JH (2004) Regeneration beyond the glial scar. Nat Rev Neurosci 5:146-156.

Sluka KA, Westlund KN (1993) Spinal cord amino acid release and content in an arthritis model: the effects of pretreatment with non-NMDA, NMDA, and NK1 receptor antagonists. Brain Res 627:89-103.

Sroga JM, Jones TB, Kigerl KA, McGaughy VM, Popovich PG (2003) Rats and mice exhibit distinct inflammatory reactions after spinal cord injury. J Comp Neurol 462:223-240.

Stirling DP, Khodarahmi K, Liu J, McPhail LT, McBride CB, Steeves JD, Ramer MS, Tetzlaff W (2004) Minocycline treatment reduces delayed oligodendrocyte death, attenuates axonal dieback, and improves functional outcome after spinal cord injury. J Neurosci 24:2182-2190.

Stirling DP, Koochesfahani KM, Steeves JD, Tetzlaff W (2005) Minocycline as a neuroprotective agent. Neuroscientist 11:308-322.

Stuesse SL, Crisp T, McBurney DL, Schechter JB, Lovell JA, Cruce WL (2001) Neuropathic pain in aged rats: behavioral responses and astrocytic activation. Exp Brain Res 137:219-227.

Svensson CI, Hua XY, Protter AA, Powell HC, Yaksh TL (2003) Spinal p38 MAP kinase is necessary for NMDA-induced spinal PGE(2) release and thermal hyperalgesia. NeuroReport 14:1153-1157.

Tanga FY, Raghavendra V, DeLeo JA (2004) Quantitative real-time RTPCR assessment of spinal microglial and astrocytic activation markers in a rat model of neuropathic pain. Neurochem Int 45:397-407.

Teng YD, Choi H, Onario RC, Zhu S, Desilets FC, Lan S, Woodard EJ, Snyder EY, Eichler ME, Friedlander RM (2004) Minocycline inhibits contusion-triggered mitochondrial cytochrome $\mathrm{c}$ release and mitigates functional deficits after spinal cord injury. Proc Natl Acad Sci USA 101:3071-3076.

Tsuda M, Shigemoto-Mogami Y, Koizumi S, Mizokoshi A, Kohsaka S, Salter MW, Inoue K (2003) P2X4 receptors induced in spinal microglia gate tactile allodynia after nerve injury. Nature 424:778-783.

Tsuda M, Mizokoshi A, Shigemoto-Mogami Y, Koizumi S, Inoue K (2004) Activation of p38 mitogen-activated protein kinase in spinal hyperactive microglia contributes to pain hypersensitivity following peripheral nerve injury. Glia 45:89-95.

Wang XJ, Kong KM, Qi WL, Ye WL, Song PS (2005) Interleukin-1 beta induction of neuron apoptosis depends on $\mathrm{p} 38$ mitogen-activated protein kinase activity after spinal cord injury. Acta Pharmacol Sin 26:934-942.

Watanabe T, Yamamoto T, Abe Y, Saito N, Kumagai T, Kayama H (1999) Differential activation of microglia after experimental spinal cord injury. J Neurotrauma 16:255-265.

Watkins LR, Milligan ED, Maier SF (2001) Glial activation: a driving force for pathological pain. Trends Neurosci 24:450-455.

Waxman SG, Hains BC (2006) Fire and phantoms after spinal cord injury: sodium channels and central pain. Trends Neurosci, in press.

Wells JE, Hurlbert RJ, Fehlings MG, Yong VW (2003) Neuroprotection by minocycline facilitates significant recovery from spinal cord injury in mice. Brain 126:1628-1637.

Winkelstein BA, DeLeo JA (2002) Nerve root injury severity differentially modulates spinal glial activation in a rat lumbar radiculopathy model: considerations for persistent pain. Brain Res 956:294-301.

Xu XJ, Dalsgaard CJ, Wiesenfeld-Hallin Z (1992) Spinal substance P and $\mathrm{N}$-methyl-D-aspartate receptors are coactivated in the induction of central sensitization of the nociceptive flexor reflex. Neuroscience 51:641-648.

Yong VW, Wells J, Giuliani F, Casha S, Power C, Metz LM (2004) The promise of minocycline in neurology. Lancet Neurol 3:744-751.

Zai LJ, Wrathall JR (2005) Cell proliferation and replacement following contusive spinal cord injury. Glia 50:247-257.

Zhang SC, Goetz BD, Duncan ID (2003) Suppression of activated microglia promotes survival and function of transplanted oligodendroglial progenitors. Glia 41:191-198. 